\title{
BMJ Open Risk factors associated with early childhood caries among Wenzhou preschool children in China: a prospective, observational cohort study
}

\author{
Liqin Mei, ${ }^{1}$ Hongying Shi, ${ }^{2}$ Zhiyuan Wei, ${ }^{1}$ Qiao Li, ${ }^{1}$ Xiping Wang (D) ${ }^{1}$
}

To cite: Mei L, Shi H, Wei Z, et al. Risk factors associated with early childhood caries among Wenzhou preschool children in China: a prospective, observational cohort study. BMJ Open 2021;11:e046816. doi:10.1136/ bmjopen-2020-046816

- Prepublication history and additional supplemental materia for this paper are available online. To view these files, please visit the journal online (http://dx.doi.org/10.1136/ bmjopen-2020-046816).

Received 10 November 2020 Accepted 09 August 2021

Check for updates

(C) Author(s) (or their employer(s)) 2021. Re-use permitted under CC BY-NC. No commercial re-use. See rights and permissions. Published by BMJ.

${ }^{1}$ Department of Preventive and Pediatric Dentistry, School \& Hospital of Stomatology, Wenzhou Medical University, Wenzhou, Zhejiang, China ${ }^{2}$ Department of Preventive Medicine, School of Public Health and Management, Wenzhou Medical University, Wenzhou, Zhejiang, China

Correspondence to

Dr Xiping Wang;

wxptell@sina.com

\section{ABSTRACT}

Objectives Early childhood caries (ECC) is a serious health public problem that affects a large proportion of children in China. This study aimed to assess risk factors for the incidence of ECC among Wenzhou (China) preschoolers.

Design Prospective, observational cohort study.

Setting Kindergartens $(n=6)$ in Wenzhou, China.

Participants 606 children who were $3-4$ years of age and newly arrived in the kindergartens in September 2011. Methods This was a longitudinal observational study with a 2-year follow-up of preschoolers of 3-4 years of age in Wenzhou (Southeast China). Oral health data were collected annually after the baseline survey. The risk factors associated with visible caries and increment of decayed, missing and filled teeth (dmft) were analysed through univariable and multivariable regression using generalised estimating equations.

Results The prevalence of ECC was increasing during the follow-up period ( $59.8 \%$ at enrolment, $71.8 \%$ at first year, and $76.4 \%$ at second year). Older age $(b=0.07$; $95 \% \mathrm{Cl}: 0.05$ to $0.09 ; \mathrm{p}<0.001$ ), caregivers (relatives or nannies) ( $b=-1.20 ; 95 \% \mathrm{Cl}:-2.23$ to $-0.16 ; \mathrm{p}=0.023)$, lower annual family income ( $¥ 10000-¥ 20000$ : $b=2.04$; $95 \% \mathrm{Cl}: 1.04$ to $3.04 ; p<0.001 ;<¥ 10000: b=1.78 ; 95 \%$ $\mathrm{Cl}: 0.65$ to $2.92 ; p=0.002$ ) and more frequent consumption of sugary snacks/drinks at night (sometimes: $b=0.88$; 95\% Cl: 0.20 to $1.56 ; p=0.011$; always: $b=1.19 ; 95 \% \mathrm{Cl}$ : 0.13 to $2.25 ; p=0.028)$ were independently associated with the increments of dmft. Older age $(0 \mathrm{R}=1.04,95 \% \mathrm{Cl}$ : 1.03 to $1.05, p<0.001$ ) and more frequent consumption of sweet snacks $(0 \mathrm{R}=1.86,95 \% \mathrm{Cl}: 1.06$ to $3.27 ; \mathrm{p}=0.030)$ were independently associated with a higher risk of visible caries.

Conclusions The occurrence and severity of ECC were associated with older age, caregivers (relatives or nannies), lower annual family income and more frequent consumption of sweet snacks. It is imperative to strengthen oral health education for parents and limit sugary foods/snacks.

\section{INTRODUCTION}

Early childhood caries (ECC) is the development of dental caries in primary teeth of children $<6$ years of age. ${ }^{1}$ It is a common disease affecting the oral health-related quality of life
Strengths and limitations of this study

- This is the first study assessed the impact of dietary lifestyle, oral health behaviours and socioeconomic characteristics on the incidence of early childhood caries in preschoolers of 3-4 years of age in Wenzhou, China.

- Since the age of children would be a significant confounder, participants in this study were preschoolers aged 3-4 years.

- The sample size of this study was sufficient and the rate of lost to follow-up was controlled.

- The study sample was selected from a limited geographical area; therefore, it may not be regarded as representative of the children of that age living in Wenzhou.

- In this study, oral microbiology was not assessed; a study showed that a higher rate of Streptococcus mutans was associated with caries in Chinese children.

of young people. ${ }^{2}{ }^{3}$ In the past 10 years, the prevalence of ECC among 5-year-old children has been rising in China, with the rate of caries rising from $66.0 \%$ to $71.9 \% .^{45}$

Dental caries is a chronic and multifactorialinduced infectious disease. ${ }^{6-8}$ Evidence from the literature indicates that low family socioeconomic status (SES), consumption of sugary food and beverages, poor oral hygiene status and high level of Streptococcus mutans bacteria are associated with ECC. ${ }^{9-11}$ Warren et $a l^{12}$ observed that frequent consumption of sugary beverages was a significant risk factor for ECC. Similarly, Johansson et $a l^{13}$ reported that the frequent consumption of sweet snacks increased the occurrence of ECC.

The relationship between SES and ECC has been shown in previous studies, which concluded that low SES was the main risk factor for ECC. ${ }^{1415}$ A cross-sectional study conducted in the United Arab Emirates found that the mean numbers of decayed, missing and filled teeth (dmft) of preschool children 
were associated with the parents' perceptions about their child's dental status and maternal education. ${ }^{16}$ Kato $e t ~ a l l^{15}$ found that parental education and family income were inversely associated with the prevalence of ECC in children. According to the National Health and Nutrition Examination Survey, children who lived in poverty had higher rates of caries than those who did not. ${ }^{17}$ Nevertheless, children with higher monthly family incomes still have a high risk of caries, ${ }^{18}$ suggesting that other multiple factors could be involved in the incidence of ECC.

Due to the difficulty of conducting longitudinal studies, there is relatively few available data describing the relationship between risk factors and the incidence of ECC. Zhou et $a l^{18}$ stated that the incidence of ECC could be related to socioeconomic, behavioural and biological factors. A cohort study conducted in African-American preschoolers aged 3-22 months indicated that an increased incidence of ECC was associated with more frequent consumption of sweets, lower frequency of toothbrushing, occasionally or no fruit juice and a history of a visit to a dentist. ${ }^{19}$

Longitudinal studies represent the study design of choice to analyse the risk of dental caries for the exposure factors during an individual's lifetime. Therefore, this longitudinal study aimed to assess the impact of dietary lifestyle, oral health behaviours and socioeconomic characteristics on the occurrence and severity of ECC in preschool children.

\section{METHODS}

\section{Study design and population}

This was a longitudinal observational study that started in October 2011 and with a 2-year follow-up in Wenzhou (Southeast China). The study was led by the Department of Preventive and Pediatric Dentistry, School and Hospital of Stomatology, Wenzhou Medical University. There are three districts in Wenzhou: Lucheng, Longwan and Ouhai. Each district was divided into developed and developing regions according to the per capita income. A kindergarten was sampled randomly from one developed and one developing region in each district, and finally, six kindergartens were included in this study.

Children who were 3-4 years of age and newly arrived in the kindergarten in September 2011 were enrolled after discussion with their parents, who accepted the oral cavity examination for up to 2 years. Exclusion criteria were children who were not resident or had systemic disease (such as cardiovascular and cerebrovascular disease, epilepsy and leukaemia), which has an impact on the data integrity and/or the safety of the participant.

Written informed consent was obtained from all children's parents.

\section{Sample size}

The prevalence of ECC in 5-year-old children was $66 \%$ in China. ${ }^{4}$ Since the subjects were $3-4$ years old, the estimated prevalence of dental caries would be less than $66 \%$. The calculation of the sample size was based on an estimate of the prevalence of ECC $50 \% .^{20}$ It resulted in 500 children, considering a power of $90 \%$, a significant difference level of $5 \%$ and attrition of $20 \%$.

\section{Dental examination and diagnostic criteria}

The oral examinations were conducted by a single examiner under natural light in a bright classroom in the kindergarten. The examinations were performed annually for 2 years. In well-lit premises, the dental examination was performed with a dental mirror and probe after drying the teeth with a sterile dry cotton ball. The number of $\mathrm{dmft}$ and the number of dmft surface (dmfs) were recorded. The examiner evaluated caries using $\mathrm{dmft}$ and dmfs according to the WHO criteria. ${ }^{21}$ Dental caries was found by visual examination without an X-ray. The examiner was trained and calibrated against a goldstandard examiner. Every examination period, $10 \%$ of the participants were re-examined. Kappa scores for the reproducibility of the single examiner for each wave of exams were $0.96,0.98$ and 0.96 , respectively.

\section{Data collection}

Oral examination was conducted by a single examiner and recorded by another dentist in the kindergarten (online supplemental appendix 1). Data on caries-related factors were collected by structured questionnaires (online supplemental appendix 2/online supplemental appendix 3). Questionnaires were distributed to parents or other guardians annually after the oral examination and were collected the following day. The collected data included dietary habits (consumption of carbonated beverage, sweet snacks, and candies/chocolate, and consumption of sugary snack/drinks at night), feeding habits (breastfed or not and sleeping with a bottle), children's oral hygiene behaviours (age tooth brushing started and frequency of toothbrushing), parental oral health practices (parents helped with tooth brushing and checked after tooth brushing), caregivers (who took care of the child, such as parents, grandparents, relatives or nannies), dental services and SES (annual family income and mother's education level). Moreover, a 5-item knowledge survey on dental caries was used to assess parental knowledge on oral health. The score of each correct answer is 1 point, and the score of oral health knowledge was calculated by the sum of the scores of the five questions. The scores on oral health knowledge were classified as poor (score 0-2), intermediate (score 3) or good (score 4-5). The design of the questionnaire was based on the national Third Oral Health Questionnaire.

\section{Statistical analysis}

All collected data were entered in EpiData software, V.3.1. Continuous variables were described using means and SDs. Categorical data were presented as counts and percentages. EmpowerStats (X\&Y Solutions, Wilmington, Delaware, USA) and R software V.2.11.1 (The R Project for Statistical Computing, www.r-project.org) were used for statistical analysis. Considering the non-independent 
characteristic of the repeated measurements on the same subject over time, the correlates of possible risk factors and the outcome of visible caries and dmft were examined with univariable and multivariable regression using generalised estimating equations. The ORs with $95 \%$ CIs are reported. Two-sided values of $\mathrm{p}<0.05$ were considered statistically significant.

\section{Patient and public involvement statement}

Not applicable.

\section{RESULTS}

\section{Characteristics of the participants}

A total of 606 resident children of 3-4 years of age were enrolled, and 87 non-resident children who did not complete at least two oral examinations were excluded in the study, resulting in a participation rate of $87.4 \%$. There were 278 girls $(47.9 \%)$ and 328 boys $(52.1 \%)$. The response rates of annual dental examination were 445 $(73.4 \%), 584(96.4 \%)$ and $560(92.4 \%)$. The reason for not completing the oral examination was that the child was absent on the examination day or had odontophobia. The recovery rates of annual valid questionnaires were $362(59.7 \%), 389(64.2 \%)$ and $370(61.1 \%)$, respectively. Of the 606 participants, 57 children without questionnaire data were not included in the risk factor analysis. Combining dental examination data and questionnaire data, the final risk factor analysis was based on a total of 549 children.

Table 1 presents the characteristics of the children and their parents. The questionnaires were mostly filled by the mothers $(70.2 \%-73.8 \%)$. Most mothers had $<12$ years of education (44.8\%-54.8\%). The prevalence of ECC in the children of 3-4 years of age was $59.8 \%$. After 1 year of follow-up, the prevalence increased to $71.8 \%$. After 2 years of follow-up, the prevalence increased to $76.4 \%$.

\section{Univariable analyses}

Univariable analyses (tables 2 and 3) on the incidence density of a tooth developing caries showed that children who were taken care of by others (relatives or nannies) had lower increments of $\mathrm{dmft}(\mathrm{b}=-1.27$; 95\% CI: -2.28 to $-0.26 ; \mathrm{p}=0.014$, table 2$)$. Lower annual family income (¥10 000-¥20 000: b=1.97; 95\% CI: 0.94 to $2.99 ; \mathrm{p}<0.001$; $<¥ 10$ 000: $\mathrm{b}=1.79 ; 95 \%$ CI: 0.65 to $2.93 ; \mathrm{p}=0.002$, table 2 ), consumption of sweet snacks $>1$ time/day $(\mathrm{b}=1.12$; 95\% CI: 0.08 to 2.16 ; $p=0.035$, table 3 ), more frequent consumption of sugary snack/drinks at night (sometimes: $\mathrm{b}=0.97 ; 95 \%$ CI: 0.31 to $1.64 ; \mathrm{p}=0.004$; always: $\mathrm{b}=1.56 ; 95 \%$ CI: 0.50 to 2.62; $\mathrm{p}=0.004$, table 3 ) and parental checking after toothbrushing (sometimes) ( $\mathrm{b}=0.69 ; 95 \%$ CI: 0.10 to 1.28 ; $p=0.021$, table 2 ) were associated with higher increments of dmft.

Univariable analyses for visible caries showed that children whose mother had more than 15 years of education experience had a lower risk of dental caries $(\mathrm{OR}=0.59$, 95\% CI: 0.37 to $0.96 ; \mathrm{p}=0.033$, table 2 ). Children who consumed sweetened snacks more than once a day had a higher risk of dental caries $(\mathrm{OR}=2.02,95 \%$ CI: 1.15 to $3.55 ; \mathrm{p}=0.015$, table 3 ). Children who consumed sugary snacks/drinks at night frequently had a higher risk of dental caries $(\mathrm{OR}=1.78,95 \%$ CI: 1.09 to 2.90; $\mathrm{p}=0.020$, table 3$)$.

\section{Multivariable analyses}

The multivariable model (table 4) for the increments of $\mathrm{dmft}$ showed that older age ( $\mathrm{b}=0.07 ; 95 \%$ CI: 0.05 to 0.09 ; $\mathrm{p}<0.001$ ), caregivers (relatives or nannies) ( $b=-1.20 ; 95 \%$ CI: -2.23 to $-0.16 ; \mathrm{p}=0.023$ ), lower annual family income

\begin{tabular}{|c|c|c|c|}
\hline Variables & Baseline & First follow-up & Second follow-up \\
\hline \multicolumn{4}{|c|}{ Questionnaire completers, n (\%) } \\
\hline Father & $84(23.1)$ & $79(20.3)$ & $74(20.0)$ \\
\hline Mother & $267(73.8)$ & $273(70.2)$ & 266 (71.9) \\
\hline Others & $11(3.0)$ & $37(9.5)$ & $30(8.1)$ \\
\hline \multicolumn{4}{|c|}{ Mother's educational level (years), $\mathrm{n}(\%)$} \\
\hline$<12$ & $162(44.8)$ & $213(54.8)$ & $195(52.7)$ \\
\hline $13-15$ & $97(27.8)$ & $91(23.4)$ & $82(22.2)$ \\
\hline$>15$ & $103(28.5)$ & $85(21.9)$ & $93(25.1)$ \\
\hline \multicolumn{4}{|l|}{ Children } \\
\hline \multicolumn{4}{|l|}{ Sex, n (\%) } \\
\hline Male & $237(53.3)$ & $313(53.6)$ & $305(54.5)$ \\
\hline Female & $208(46.7)$ & $271(46.4)$ & $255(45.5)$ \\
\hline \multicolumn{4}{|l|}{ Caries, n (\%) } \\
\hline Without caries & $179(40.2)$ & $165(28.3)$ & $132(23.6)$ \\
\hline With caries & $266(59.8)$ & $419(71.8)$ & $428(76.4)$ \\
\hline
\end{tabular}


Table 2 Univariable analyses between sociodemographic status, parental oral health behaviour, parental oral health knowledge level and ECC

\begin{tabular}{|c|c|c|c|c|c|}
\hline \multirow{2}{*}{ Variables } & & \multicolumn{2}{|l|}{$\mathrm{dmft}$} & \multicolumn{2}{|c|}{ Experience of caries } \\
\hline & & b (95\% Cl) & $P$ value & OR $(95 \% \mathrm{Cl})$ & $P$ value \\
\hline \multicolumn{6}{|c|}{ Mother's education level (years), n (\%) } \\
\hline$<12^{*}$ & $262(23.4)$ & 0 & & 1 & \\
\hline $13-15$ & $578(51.6)$ & $-0.36(-1.19$ to 0.47$)$ & 0.395 & $0.93(0.61$ to 1.40$)$ & 0.717 \\
\hline$>15$ & $281(25.1)$ & $-0.48(-1.53$ to 0.56$)$ & 0.366 & 0.59 (0.37 to 0.96$)$ & 0.033 \\
\hline \multicolumn{6}{|c|}{ Annual family income (¥), n (\%) } \\
\hline$>¥ 20000^{*}$ & $33(2.9)$ & 0 & & 1 & \\
\hline$¥ 10000-¥ 20000$ & $833(74.3)$ & 1.97 (0.94 to 2.99$)$ & $<0.001$ & $1.43(0.63$ to 3.26$)$ & 0.392 \\
\hline$<¥ 10000$ & $255(22.8)$ & 1.79 (0.65 to 2.93$)$ & 0.002 & 1.35 (0.57 to 3.21$)$ & 0.493 \\
\hline \multicolumn{6}{|l|}{ Caregiver, n (\%) } \\
\hline Parents & $776(69.2)$ & 0 & & 1 & \\
\hline Grandparents & $304(27.1)$ & $0.51(-0.31$ to 1.33$)$ & 0.220 & 1.09 (0.75 to 1.59$)$ & 0.658 \\
\hline Relatives or nannies & $41(3.7)$ & $-1.27(-2.28$ to -0.26$)$ & 0.014 & 0.91 (0.39 to 2.13$)$ & 0.834 \\
\hline \multicolumn{6}{|c|}{ Parents help with tooth brushing, $n(\%)$} \\
\hline Once a day* & $204(18.2)$ & 0 & & 1 & \\
\hline Once a week & $126(11.2)$ & $0.37(-0.54$ to 1.28$)$ & 0.428 & 1.13 (0.68 to 1.90$)$ & 0.630 \\
\hline Sometimes & $662(59.1)$ & $0.23(-0.48$ to 0.95$)$ & 0.519 & 1.08 (0.75 to 1.55$)$ & 0.673 \\
\hline Never & $129(11.5)$ & $0.52(-0.54$ to 1.59$)$ & 0.337 & 1.07 (0.63 to 1.81$)$ & 0.807 \\
\hline \multicolumn{6}{|c|}{ Parental check after tooth brushing, $\mathrm{n}(\%)$} \\
\hline$\geq 1$ time/week* & $289(25.8)$ & 0 & & 1 & \\
\hline$<1$ time/week & $832(74.2)$ & 0.69 (0.10 to 1.28$)$ & 0.021 & $1.24(0.90$ to 1.70$)$ & 0.192 \\
\hline \multicolumn{6}{|c|}{ Parental oral health knowledge level, $\mathrm{n}(\%)$} \\
\hline Poor & $221(19.7)$ & 0 & & 1 & \\
\hline Intermediate & $557(49.6)$ & $-0.11(-0.87$ to 0.65$)$ & 0.777 & $0.87(0.61$ to 1.24$)$ & 0.436 \\
\hline Good & $344(30.7)$ & $0.28(-0.55$ to 1.10$)$ & 0.509 & $1.21(0.80$ to 1.84$)$ & 0.370 \\
\hline
\end{tabular}

${ }^{*}$ Reference group.

dmft, decayed, missing and filled teeth; ECC, early childhood caries.

(¥10 000-¥20 000: b=2.04; 95\% CI: 1.04 to $3.04 ; \mathrm{p}<0.001$; $<¥ 10000: \mathrm{b}=1.78$; $95 \%$ CI: 0.65 to $2.92 ; \mathrm{p}=0.002)$ and more frequent consumption of sugary snacks/drinks at night (sometimes: $\mathrm{b}=0.88$; $95 \%$ CI: 0.20 to 1.56 ; $\mathrm{p}=0.011$; always: $\mathrm{b}=1.19$; $95 \%$ CI: 0.13 to 2.25 ; $\mathrm{p}=0.028$ ) were independently associated with the increments of $\mathrm{dmft}$.

The multivariable model (table 4) for visible caries showed that older age $(\mathrm{OR}=1.04,95 \%$ CI: 1.03 to 1.05 ; $\mathrm{p}<0.001)$ and more frequent consumption of sweet snacks $(\mathrm{OR}=1.86,95 \%$ CI: 1.06 to $3.27 ; \mathrm{p}=0.030)$ were independently associated with a higher risk of visible caries.

\section{DISCUSSION}

ECC is a serious health public problem that affects a large proportion of children in China. ${ }^{45}$ This study aimed to assess risk factors for the incidence of ECC among Wenzhou (China) preschoolers. The results showed that the occurrence and severity of ECC were associated with older age, caregivers (relatives or nannies), lower annual family income and consumption of sweet snacks. Those results are supported by other studies on ECG. ${ }^{22} 23$

Most studies reported an association between ECC and frequent consumption of sweets. ${ }^{12} 1324$ This study reported that children who ate sweet snacks frequently or consumed sugary snacks/drinks at night had a higher risk of dental caries. The results are supported by previous studies. ${ }^{67121324}$ Watanabe $e t a l^{25}$ reported that the incidence of ECC was associated with the consumption of sweet snacks and sweetened beverages. The findings suggest that it is necessary to strengthen oral health education for parents and to limit the intake of sugary foods/snacks.

In this study, the multivariable analysis showed a lower increment of dmft among children who were taken care of by relatives or nannies. It was reported that children who were taken care of primarily by grandparents had higher dmft increments. ${ }^{26}$ Children whose mother worked in professional and engineering or service had 
Table 3 Univariable analyses between dietary information, oral hygiene practices and ECC

\begin{tabular}{|c|c|c|c|c|c|}
\hline \multirow{2}{*}{ Variables } & & \multirow{2}{*}{$\frac{\mathrm{dmft}}{\mathrm{b}(95 \% \mathrm{Cl})}$} & \multirow[b]{2}{*}{$P$ value } & \multicolumn{2}{|c|}{ Experience of caries } \\
\hline & & & & OR $(95 \% \mathrm{Cl})$ & $P$ value \\
\hline \multicolumn{6}{|l|}{ Breastfed or not, n (\%) } \\
\hline Breastfed $^{*}$ & $248(22.1)$ & 0 & & 1 & \\
\hline Breastfed mainly & $199(17.8)$ & $-0.16(-1.07$ to 0.76$)$ & 0.738 & 0.98 (0.63 to 1.53$)$ & 0.946 \\
\hline Mixed feed & $248(22.1)$ & $-0.73(-1.63$ to 0.16$)$ & 0.107 & $0.92(0.59$ to 1.44$)$ & 0.724 \\
\hline Formula feed mainly & $162(14.5)$ & $-0.34(-1.42$ to 0.74$)$ & 0.538 & 0.99 (0.59 to 1.67$)$ & 0.977 \\
\hline Formula feed & $264(23.6)$ & $-0.07(-1.07$ to 0.93$)$ & 0.886 & 1.25 (0.77 to 2.03$)$ & 0.359 \\
\hline \multicolumn{6}{|c|}{ Consumption of carbonated beverage, $n(\%)$} \\
\hline$<1$ time/day* & $981(87.5)$ & 0 & & 1 & \\
\hline 1 time/day & $100(8.9)$ & $0.21(-0.71$ to 1.14$)$ & 0.651 & 1.19 (0.70 to 2.02 & 0.523 \\
\hline$>1$ time/day & $40(3.6)$ & $0.45(-0.89$ to 1.79$)$ & 0.510 & 1.77 (0.81 to 3.89$)$ & 0.155 \\
\hline \multicolumn{6}{|c|}{ Consumption of sweet snacks, $n(\%)$} \\
\hline$<1$ time/day* & $513(45.8)$ & 0 & & 1 & \\
\hline 1 time/day & $506(45.1)$ & $0.36(-0.25$ to 0.98$)$ & 0.246 & 1.30 (0.97 to 1.74$)$ & 0.082 \\
\hline$>1$ time/day & $102(9.1)$ & 1.12 (0.08 to 2.16$)$ & 0.035 & 2.02 (1.15 to 3.55$)$ & 0.015 \\
\hline \multicolumn{6}{|c|}{ Consumption of candies/chocolate, $\mathrm{n}(\%)$} \\
\hline$<1$ time/day * & $848(75.7)$ & 0 & & 1 & \\
\hline 1 time/day & $215(19.2)$ & $0.64(-0.09$ to 1.38$)$ & 0.087 & 1.37 (0.92 to 2.03$)$ & 0.119 \\
\hline$>1$ time/day & $58(5.2)$ & $0.48(-0.85$ to 1.84$)$ & 0.479 & 1.54 (0.76 to 3.10$)$ & 0.233 \\
\hline \multicolumn{6}{|c|}{ Sugary snack/drinks at night, $\mathrm{n}(\%)$} \\
\hline Never ${ }^{\star}$ & $225(20.1)$ & 0 & & 1 & \\
\hline Sometimes & $712(63.5)$ & 0.97 (0.31 to 1.64$)$ & 0.004 & 1.40 (0.98 to 2.00$)$ & 0.063 \\
\hline Always & $184(16.4)$ & 1.56 (0.50 to 2.62$)$ & 0.004 & 1.78 (1.09 to2.90) & 0.020 \\
\hline \multicolumn{6}{|l|}{ Slept with bottles, n (\%) } \\
\hline Never $^{\star}$ & $942(84.1)$ & 0 & & 1 & \\
\hline Sometimes & $110(9.8)$ & $0.95(-0.07$ to 1.97$)$ & 0.069 & 1.47 (0.91 to 2.38$)$ & 0.118 \\
\hline Always & $68(6.1)$ & $0.42(-1.04$ to 1.88$)$ & 0.573 & 1.13 (0.57 to 2.25$)$ & 0.725 \\
\hline \multicolumn{6}{|c|}{ Age toothbrushing started, $\mathrm{n}(\%)$} \\
\hline 1 year old ${ }^{*}$ & $48(4.3)$ & 0 & & 1 & \\
\hline 2 years old & $152(13.6)$ & $-0.01(-1.82$ to 1.81$)$ & 0.993 & 0.93 (0.46 to 1.88$)$ & 0.837 \\
\hline 3 years old & $836(74.6)$ & $0.81(-0.99$ to 2.61$)$ & 0.379 & 1.38 (0.68 to 2.81$)$ & 0.371 \\
\hline Never & $85(7.6)$ & $1.01(-1.08$ to 3.11$)$ & 0.343 & $1.39(0.57$ to 3.37$)$ & 0.469 \\
\hline \multicolumn{6}{|c|}{ Frequency of toothbrushing, $\mathrm{n}(\%)$} \\
\hline$\geq 2$ time/day* & $209(18.6)$ & 0 & & 1 & \\
\hline 1 time/day & $419(37.4)$ & $0.11(-0.68$ to 0.90$)$ & 0.793 & 0.95 (0.63 to 1.45$)$ & 0.825 \\
\hline$<1$ time/day & $450(40.1)$ & $0.36(-0.53$ to 1.25$)$ & 0.430 & 0.94 (0.61 to 1.46$)$ & 0.792 \\
\hline Never & $43(3.8)$ & $0.50(-1.42$ to 2.42$)$ & 0.611 & 0.84 (0.37 to 1.91$)$ & 0.677 \\
\hline
\end{tabular}

${ }^{\star}$ Reference group.

$\mathrm{dmft}$, decayed, missing and filled teeth; ECC, early childhood caries.

lower rates of dental caries than those whose mother was unemployed. ${ }^{15}$ When the caregiver was not a parent or grandparent but someone else (a relative or a nanny), the family had to bear the cost of hiring that person, indicating that the family had sufficient income. Compared with the elderly, relatives or nannies might have higher compliance and better service awareness, and they might be more responsible for children's oral health.

Our findings showed that children with a lower family income had a higher increment of $\mathrm{dmft}$ and children whose mother had more than 15 years of education experience had a lower risk of dental caries, as supported by 
Table 4 Risk factors associated with the increment of dmft and the experience of caries analysed by generalised estimating equation

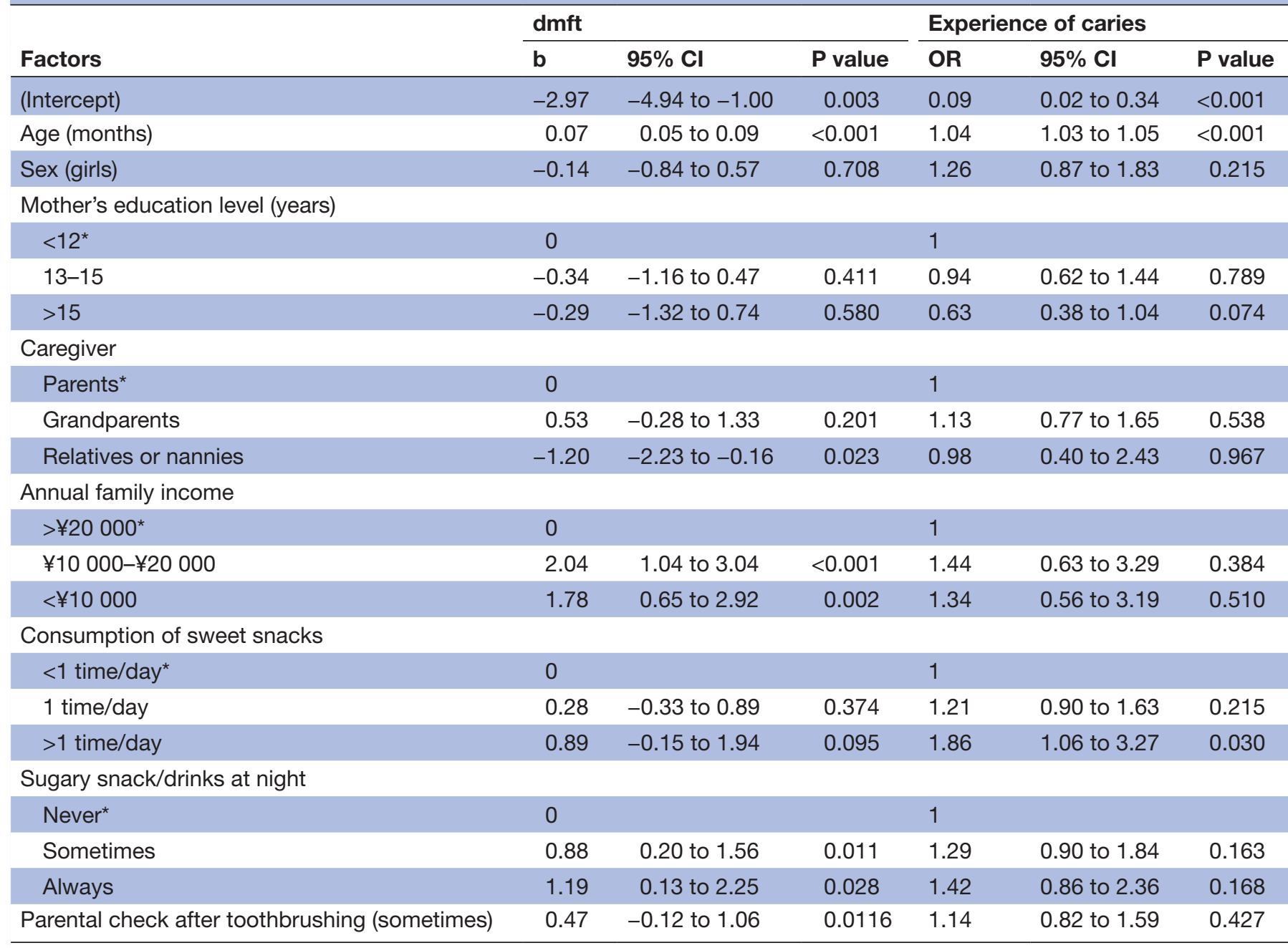

*Reference group.

dmft, decayed, missing and filled teeth.

the previous studies. ${ }^{15} 27$ Nevertheless, the underlying mechanism of the influence of the SES on dental caries still needs to be defined. Parental SES might affect the prevalence of ECC through parental oral health knowledge and practices. ${ }^{28}$ Educated mothers are more likely to know how to protect their children from dental caries. Patients with special needs and difficulty accessing oral health services seems to have higher rates of dental caries. $^{29}$ Clearly, these issues warrant further research, including further analyses of the present study's data. Whether there is a relationship between parental SES and oral health behaviours remains unknown.

There were some limitations to this study. First, some information bias and recall bias were inevitable in this investigation. Second, some people might sometimes respond to questionnaires based on general social norms rather than actual situations because they attempt to adhere to what is socially desirable. Third, there was some selection bias. The study sample was selected from a limited geographic area. Therefore, it may not be regarded as representative of the children of that age living in Wenzhou. Fourth, oral microbiology was not assessed; a study showed that high rates of plaque mutans streptococci were associated with carries in Chinese children. ${ }^{30}$ Finally, due to the high prevalence of dental caries among 3-4 years old children, further research in younger children was necessary.

\section{CONCLUSIONS}

The occurrence and severity of ECC were associated with older age, caregivers (relatives or nannies), lower annual family income and more frequent consumption of sweet snacks. The findings indicated that lower SES and more frequent consumption of sweet snacks had a significant impact on the occurrence and severity of ECC.

Acknowledgements We would like to thank the staff of the kindergartens. We would also like to thank the preschool children and their parents for their participation in this study. 
Contributors LM designed the study, carried out the dental examinations and drafted the manuscript. HS performed the statistical analysis and helped draft the manuscript. ZW participated in the study design and helped carry out the examinations. QL collected the data and helped draft the manuscript. XW carried out the examinations, collected data and drafted the manuscript. All authors read and approved the final manuscript.

Funding The study was supported by the Zhejiang province education department project (No. Y201223271).

Competing interests None declared.

Patient consent for publication Not required.

Ethics approval This study was approved by the Medical Ethics Committee of Wenzhou Medical University (WYKQ2013003).

Provenance and peer review Not commissioned; externally peer reviewed.

Data availability statement Data are available on reasonable request. All data relevant to the study are included in the article or uploaded as online supplemental information. All data relevant to the study are included in the article or uploaded as supplementary information.

Supplemental material This content has been supplied by the author(s). It has not been vetted by BMJ Publishing Group Limited (BMJ) and may not have been peer-reviewed. Any opinions or recommendations discussed are solely those of the author(s) and are not endorsed by BMJ. BMJ disclaims all liability and responsibility arising from any reliance placed on the content. Where the content includes any translated material, BMJ does not warrant the accuracy and reliability of the translations (including but not limited to local regulations, clinical guidelines, terminology, drug names and drug dosages), and is not responsible for any error and/or omissions arising from translation and adaptation or otherwise.

Open access This is an open access article distributed in accordance with the Creative Commons Attribution Non Commercial (CC BY-NC 4.0) license, which permits others to distribute, remix, adapt, build upon this work non-commercially, and license their derivative works on different terms, provided the original work is properly cited, appropriate credit is given, any changes made indicated, and the use is non-commercial. See: http://creativecommons.org/licenses/by-nc/4.0/.

\section{ORCID iD}

Xiping Wang http://orcid.org/0000-0003-4185-948X

\section{REFERENCES}

1 Policy on early childhood caries (ECC): classifications, consequences, and preventive strategies. Pediatr Dent 2016;38:52-4.

2 Kawashita Y, Kitamura M, Saito T. Early childhood caries. Int J Dent 2011;2011:1-7.

3 Martins-Júnior PA, Vieira-Andrade RG, Corrêa-Faria P, et al. Impact of early childhood caries on the oral health-related quality of life of preschool children and their parents. Caries Res 2013;47:211-8.

4 Cao C-fan. [Prevalences of periodontal diseases and dental caries in China: re-analysis of the data from the Third National Epidemiological Survey on Oral Health]. Zhonghua Kou Qiang Yi Xue Za Zhi 2013;48:257-9.

5 Wang XFX, ZX L. Report of forth national oral health survey in China. People's Medical Publishing House 2018:12-13.

6 Maheswari SU, Raja J, Kumar A, et al. Caries management by risk assessment: a review on current strategies for caries prevention and management. J Pharm Bioallied Sci 2015;7:S320-4.

7 Hurlbutt M, Young DA. A best practices approach to caries management. J Evid Based Dent Pract 2014;14 Suppl:77-86.
8 Gomez J. Detection and diagnosis of the early caries lesion. BMC Oral Health 2015;15 Suppl 1:S3.

9 Warren JJ, Weber-Gasparoni K, Marshall TA, et al. Factors associated with dental caries experience in 1-year-old children. $J$ Public Health Dent 2008;68:70-5.

10 Warren JJ, Weber-Gasparoni K, Marshall TA, et al. A longitudinal study of dental caries risk among very young low Ses children. Community Dent Oral Epidemiol 2009;37:116-22.

11 Tsai Al, Chen C-Y, Li L-A, et al. Risk indicators for early childhood caries in Taiwan. Community Dent Oral Epidemiol 2006;34:437-45.

12 Warren JJ, Blanchette D, Dawson DV, et al. Factors associated with dental caries in a group of American Indian children at age 36 months. Community Dent Oral Epidemiol 2016;44:154-61.

13 Johansson I, Holgerson PL, Kressin NR, et al. Snacking habits and caries in young children. Caries Res 2010;44:421-30.

14 Congiu G, Campus G, Lugliè PF. Early childhood caries (ECC) prevalence and background factors: a review. Oral Health Prev Dent 2014;12:71-6.

15 Kato H, Tanaka K, Shimizu K, et al. Parental occupations, educational levels, and income and prevalence of dental caries in 3-year-old Japanese children. Environ Health Prev Med 2017;22:80.

16 Elamin A, Garemo M, Gardner A. Dental caries and their association with socioeconomic characteristics, oral hygiene practices and eating habits among preschool children in Abu Dhabi, United Arab Emirates - the NOPLAS project. BMC Oral Health 2018;18:104.

17 Vargas CM, Dye BA, Kolasny CR, et al. Early childhood caries and intake of 100 percent fruit juice: data from NHANES, 1999-2004. J Am Dent Assoc 2014;145:1254-61.

18 Zhou Y, Yang JY, Lo ECM, et al. The contribution of life course determinants to early childhood caries: a 2-year cohort study. Caries Res 2012;46:87-94.

19 Ghazal T, Levy SM, Childers NK, et al. Factors associated with early childhood caries incidence among high caries-risk children. Community Dent Oral Epidemiol 2015;43:366-74.

20 Zhou Y, Lin HC, Lo ECM, et al. Risk indicators for early childhood caries in 2-year-old children in southern China. Aust Dent $J$ 2011;56:33-9.

21 World Health Organization. Oral health surveys: basic methods. 4th edn. Geneva: World Health Organization, 1997.

22 Colak H, Dülgergil CT, Dalli M, et al. Early childhood caries update: a review of causes, diagnoses, and treatments. J Nat Sci Biol Med 2013;4:29-38.

23 Fontana M, Jackson R, Eckert $\mathrm{G}$, et al. Identification of caries risk factors in toddlers. J Dent Res 2011;90:209-14.

24 Joharji RM, Adenubi JO. Prevention of pit and fissure caries using an antimicrobial varnish: 9 month clinical evaluation. J Dent 2001;29:247-54.

25 Watanabe M, Wang D-H, ljichi A, et al. The influence of lifestyle on the incidence of dental caries among 3-year-old Japanese children. Int J Environ Res Public Health 2014;11:12611-22.

26 Chen KJ, Gao SS, Duangthip D, et al. Dental caries status and its associated factors among 5-year-old Hong Kong children: a crosssectional study. BMC Oral Health 2017;17:121.

27 Dabawala S, Suprabha BS, Shenoy R, et al. Parenting style and oral health practices in early childhood caries: a case-control study. Int $J$ Paediatr Dent 2017;27:135-44.

28 Qiu RM, Lo ECM, Zhi QH, et al. Factors related to children's caries: a structural equation modeling approach. BMC Public Health 2014;14:1071.

29 Lewis CW, Grossman DC, Domoto PK, et al. The role of the pediatrician in the oral health of children: a national survey. Pediatrics 2000;106:E84.

30 Fan C, Li M, Gan Y, et al. A simple aged score for risk classification of primary liver cancer: development and validation with longterm prospective HBsAg-positive cohorts in Qidong, China. Gut 2019;68:948-9. 